\title{
EFFECT OF VARIOUS PACKAGING SOLUTIONS ON THE QUALITY OF HAZELNUTS IN NUT-DRIED FRUIT MIXES
}

\author{
Asnate Kirse-Ozolina, Sandra Muizniece-Brasava, Jolanta Veipa* \\ Department of Food Technology, Faculty of Food Technology, Latvia University of Life Sciences and Technologies, Rigas iela 22, \\ Jelgava, Latvia,e-mail: saulej@tvnet.lv
}

\begin{abstract}
Nut-dried fruit mixes are a nutritious snack, which can be consumed throughout the year. However, moisture migration, which occurs between components with higher moisture content (dried fruit) and lower moisture content (cereals, nuts), can lead to undesirable physical and chemical changes during storage. The aim of this study was to identify optimal packaging solutions for various types of nut and dried fruit mixes in order to maintain the quality of hazelnuts. Experiments were carried out at the laboratories of the Faculty of Food Technology, Latvia University of Life Sciences and Technologies and quality control laboratories of Grindeks JSC. A total of nine packaging conditions were tested: three types of packaging - polyethylene terephthalate/metallised polyethylene terephthalate/low density polyethylene (PET/metPET/LDPE), biodegradable polylactic acid (PLA) and biaxially oriented polypropylene / ethyl vinyl alcohol / low density polyethylene (BOPP / EVOH / LDPE), and three packaging environments - air ambiance, modified atmosphere packaging $\left(30 \% \mathrm{CO}_{2}, 70 \% \mathrm{~N}_{2}\right)$ and active packaging with oxygen absorbents. The results of moisture content, $\mathrm{pH}$, hardness, colour, water activity and peroxide value testing during 8-month storage showed that the most suitable packaging materials to ensure quality of hazelnuts in nut-dried fruit mixes are biodegradable PLA and BOPP / EVOH / LDPE packaging. With regards to the effect of packaging technologies on product quality, the best results were obtained when modified atmosphere packaging or active packaging was used.
\end{abstract}

Keywords: hazelnut, biodegradable packaging, active packaging, storage

\section{Introduction}

Nuts are a good addition to the daily diet, providing unsaturated fats, protein, vitamins and minerals (O’Neil et al., 2012). In order to supplement the body with this nutritious snack, nuts are usually combined with dried fruits and sold as nut-dried fruit mixes. However, moisture migration between components with lower moisture (nuts) and higher moisture (dried fruits) can lead to undesirable physical and chemical changes, especially during storage (Pérez-Gago, Rhim, 2014).

Optimal packaging conditions can prevent products from undesirable moisture changes, growth of microorganisms, increase of free fatty acids and peroxide value, all of which affects quality and safety of products (Ozturk et al., 2016). Properties of packaging materials and quality of food have a positive correlation (McMillin, 2017), however, the question of packaging waste reduction is also important (Licciardello, 2017). Thus, packaging materials made from biopolymers are gaining their place in the market (McMillin, 2017).

Packaging environment also has an important effect on the quality of foods, as modified atmosphere environment can control oxidation of products by replacing $\mathrm{O}_{2}$ with $\mathrm{CO}_{2}$ or $\mathrm{N}_{2}$ (Ozturk et.al., 2016). Active packaging systems include moisture and $\mathrm{O}_{2}$ absorbers, and $\mathrm{CO}_{2}$ releasers (Kapetanakou, Skandamis, 2016) which in return prevents food spoilage and can prolong shelf-life.

Producers are aware of problems with packaged nutdried fruit mixes during storage, therefore, testing on the best packaging conditions are vital.

The aim of this study was to identify optimal packaging solutions for various types of nut and dried fruit mixes in order to maintain the quality of hazelnuts.

\section{Materials and Methods}

Raw materials

A total of three products were used for the research: two nut-dried fruit mixes, and hazelnuts as a control sample (Table 1), all supplied by Gemoss Ltd.

Table 1

Characterisation of products used for the research

\begin{tabular}{llcl}
\hline Products & Ingredients & $\begin{array}{c}\text { Amount, } \\
\%\end{array}$ & $\begin{array}{c}\text { Country of } \\
\text { origin }\end{array}$ \\
\hline Nut-dried & hazelnuts & 10.9 & Turkey \\
fruit mix \#1 & peanuts & 10.6 & USA \\
& almonds & 6.5 & USA \\
& royal raisins, & 23.6 & South Africa \\
& dark & & \\
& banana crisps & 17.7 & Philippines \\
& golden raisins & 17.7 & Iran \\
& dried apricots & 13.0 & Turkey \\
\hline $\begin{array}{l}\text { Nut-dried } \\
\text { fruit mix \#2 }\end{array}$ & walnuts & 34.2 & Ukraine \\
& peanuts & 15.5 & USA \\
& hazel nuts & 9.9 & Turkey \\
& almonds & 6.0 & USA \\
& royal raisins, & 20.0 & South Africa \\
& dark & & \\
& golden raisins & 14.4 & Iran \\
\hline Separately \\
packaged nuts & hazel nuts & 100.0 & Turkey \\
\hline
\end{tabular}

\section{Packaging solutions}

Three types of packaging materials were used to evaluate the quality of nuts and nut - dried fruit mixes during storage (Table 2). In addition, three packaging environments were also applied - air ambiance, modified atmosphere packaging (MAP) $\left(30 \% \mathrm{CO}_{2}\right.$, 
$70 \% \mathrm{~N}_{2}$ ) and active packaging with oxygen absorbers (AGELESS ${ }^{\circ}$ GE, oxygen absorption capacity $100 \mathrm{~cm}^{3}$ ).

Table 2

Description of packaging materials used for the research

\begin{tabular}{llc}
\hline Material & Abbreviation & $\begin{array}{c}\text { Thickness, } \\
\boldsymbol{\mu m}\end{array}$ \\
\hline $\begin{array}{l}\text { Lightproof 3-layer } \\
\text { polyethylene } \\
\text { terephthalate / metallised } \\
\text { polyethylene } \\
\begin{array}{l}\text { terephthalate / low } \\
\text { density polyethylene }\end{array}\end{array}$ & $\begin{array}{l}\text { PET / } \\
\text { metPET / }\end{array}$ & $55 \pm 2$ \\
\hline $\begin{array}{l}\text { LDPE } \\
\begin{array}{l}\text { Ceramisparent one-layer } \\
\text { with a barrier of pure } \\
\text { silicon oxide [SiOx] }\end{array}\end{array}$ & bLAdegradable & $50 \pm 2$ \\
\hline $\begin{array}{l}\text { Semi-transparent 3-layer } \\
\text { biaxially oriented } \\
\text { polypropylene / ethyl } \\
\text { vinyl alcohol / low } \\
\text { density polyethylene }\end{array}$ & BOPP / & \\
\hline
\end{tabular}

\section{Experimental design}

Experiments were carried out at the laboratories of the Faculty of Food Technology, Latvia University of Life Sciences and Technologies and quality control laboratories of Grindeks JSC.

A total of nine packaging conditions were tested (Table 3). Portion size of nut-dried fruit mixes was $100 \pm 5 \mathrm{~g}$, separately packed hazelnuts were weighed in $40 \pm 2 \mathrm{~g}$ portions (retail size). Prepared samples were stored at room temperature $\left(20 \pm 2{ }^{\circ} \mathrm{C}\right)$ under daylight conditions for 8 months. Samples were analysed on the day of packaging and every 2 months during storage; three replicates were tested per analysis.

Quality analysis

Moisture content (\%) was determined by grinding nuts in a KN 195 Knifetec $^{\mathrm{TM}}$ laboratory mill (FOSS Analytical, Denmark), drying at $105{ }^{\circ} \mathrm{C}$ for 2 hours and then weighing.

Hardness (N) was assessed with TA.HD.plus Texture Analyser (Stable Micro Systems, UK). The following parameters describe the measurements: compression plate $100 \mathrm{~mm}$, pre-test speed $1 \mathrm{~mm} \mathrm{~s}^{-1}$, test speed $30 \mathrm{~mm} \mathrm{~s}^{-1}$, distance $5 \mathrm{~mm}$, trigger force $0.049 \mathrm{~N}$.

Colour was determined with colorimeter ColorTecPCM (Accuracy Microsensors, USA) after grinding nuts in a laboratory mill. The data was processed using ColorSoft QCW software, colour was measured in CIE $\mathrm{L} * \mathrm{a}{ }^{*} \mathrm{~b} *$ system. Total colour difference was calculated using the following formula (1):

$$
\Delta E^{*}=\sqrt{\left(L^{*}-L_{0}^{*}\right)^{2}+\left(a^{*}-a_{0}^{*}\right)^{2}+\left(b^{*}-b_{0}^{*}\right)^{2}}
$$

where:

$\Delta E^{*}$ - total colour difference which characterises colour changes of nuts;

$L^{*}$ - colour intensity (light-dark) at the end of storage;

$L_{0}^{*}$ - colour intensity (light-dark) at the beginning of storage;

$a^{*}$ - green-red colour component at the end of storage; $a_{0} *$ - green-red colour component at the beginning of storage;

$b^{*}$ - blue-yellow colour component at the end of storage; $b_{0}{ }^{*}$ - blue-yellow colour component at the beginning of storage.

$\mathrm{pH}$ of nuts was assessed using Jenway $3510 \mathrm{pH}$-meter (Cole-Parmer, UK) after adding distilled water to ground nuts (10:1).

Water activity $\left(\mathrm{a}_{\mathrm{w}}\right)$ was assayed with Novasina LabSwift-aw (Novatron Scientific, UK).

Peroxide value was tested in nut oil which was pressed out of grinded nuts using hydraulic press CrushIR Digital (PIKE Technologies, USA) according to ISO 3960:2017.

Table 3

Sample codes used in the research

\begin{tabular}{|c|c|c|c|}
\hline Samples & $\begin{array}{c}\text { Packaging } \\
\text { material }\end{array}$ & $\begin{array}{c}\text { Packaging } \\
\text { environment }\end{array}$ & $\begin{array}{c}\text { Sample } \\
\text { codes }\end{array}$ \\
\hline \multirow{9}{*}{$\begin{array}{l}\text { Nut-dried } \\
\text { fruit mix } \\
\# 1\end{array}$} & PET / & active packaging & $1 \mathrm{AF}$ \\
\hline & metPET / & MAP & $1 \mathrm{GF}$ \\
\hline & LDPE & air ambience & $1 \mathrm{OF}$ \\
\hline & BOPP / & active packaging & $1 \mathrm{AC}$ \\
\hline & EVOH / & MAP & $1 \mathrm{GC}$ \\
\hline & LDPE & air ambience & $10 \mathrm{C}$ \\
\hline & PLA & active packaging & $1 \mathrm{AB}$ \\
\hline & & MAP & $1 \mathrm{~GB}$ \\
\hline & & air ambience & $10 B$ \\
\hline \multirow{9}{*}{$\begin{array}{l}\text { Nut-dried } \\
\text { fruit mix } \\
\# 2\end{array}$} & PET / & active packaging & $2 \mathrm{AF}$ \\
\hline & metPET / & MAP & $2 \mathrm{GF}$ \\
\hline & LDPE & air ambience & $2 \mathrm{OF}$ \\
\hline & BOPP / & active packaging & $2 \mathrm{AC}$ \\
\hline & EVOH / & MAP & $2 \mathrm{GC}$ \\
\hline & LDPE & air ambience & $2 \mathrm{OC}$ \\
\hline & PLA & active packaging & $2 \mathrm{AB}$ \\
\hline & & MAP & 2GB \\
\hline & & air ambience & $2 \mathrm{OB}$ \\
\hline \multirow{9}{*}{$\begin{array}{l}\text { Separately } \\
\text { packaged } \\
\text { nuts }\end{array}$} & PET / & active packaging & $4 \mathrm{AF}$ \\
\hline & metPET / & MAP & $4 \mathrm{GF}$ \\
\hline & LDPE & air ambience & $4 \mathrm{OF}$ \\
\hline & BOPP / & active packaging & $4 \mathrm{AC}$ \\
\hline & EVOH / & MAP & $4 \mathrm{GC}$ \\
\hline & LDPE & air ambience & $4 \mathrm{OC}$ \\
\hline & PLA & active packaging & $4 \mathrm{AB}$ \\
\hline & & MAP & $4 \mathrm{~GB}$ \\
\hline & & air ambience & $4 \mathrm{OB}$ \\
\hline
\end{tabular}

\section{Data processing}

The obtained data processing was performed using MS Excel v16 software; one- and two-way ANOVA was applied to determine differences within samples, Tukey's test was also used. Factors were defined as significant, if p-value was below 0.05 .

\section{Results and Discussion}

\section{Changes in moisture content in nuts}

Initial moisture content of hazel nuts was $3.58 \%$. Most noticeable moisture changes were observed in metalized packaging (PET / metPET / LDPE) for nut-dried fruit mixes \#1 and \#2 (Figure 1A, 1B) $(\mathrm{p}<0.05)$. Moisture 
content increased in metalized packaging with air ambience up to $5.17 \%$ (Figure 1A) and $4.70 \%$ (Figure 1B). BOPP/EVOH/LDPE packaging and biodegradable PLA had an insignificant effect on moisture content changes of hazelnuts during storage regardless of packaging environment $(\mathrm{p}>0.05)$.
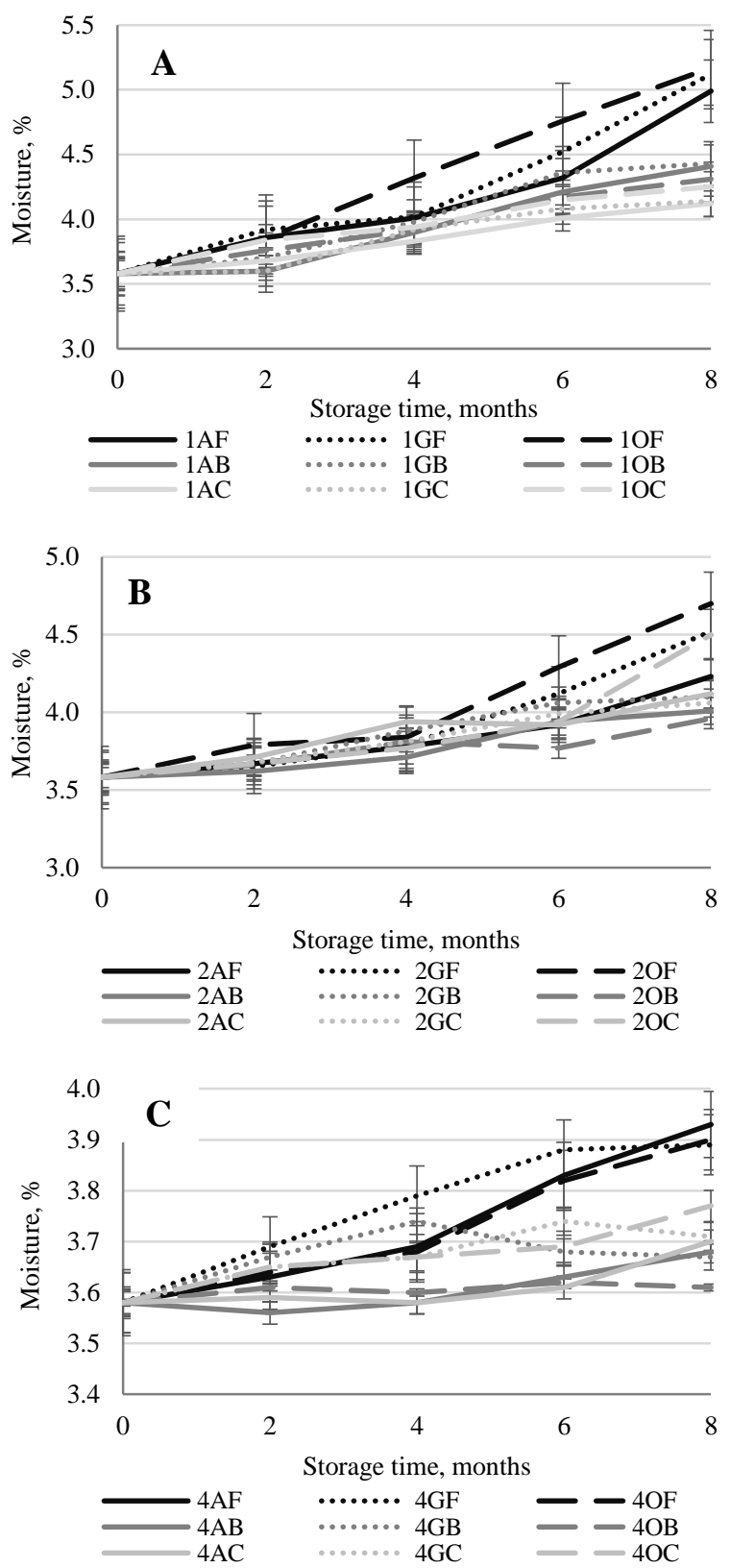

Figure 1. Moisture content dynamics in hazelnuts during storage

A - nut-dried fruit mix \#1, B - nut-dried fruit mix \#2, $\mathrm{C}$ - separately packaged nuts

Moisture changes for separately packaged hazel nuts were minimal (3.61 to $3.90 \%$ ), there were not significant differences among packaging materials and packaging environments for hazel nuts ( $p>0.05)$.

Scientific data shows that unprocessed hazelnuts contain $5.3 \%$ moisture (Herbello-Hermelo et al., 2018), while Schlörmann et al. (2015) reported $4.70 \%$ moisture for hazelnuts. Whereas, Guiné et al. (2014) showed lower moisture for hazelnuts, namely $4.05-4.10 \%$ before storage. Ghirardello et al. (2014) reported insignificant changes in hazelnut moisture during 8-month storage at ambient temperature.

Changes in $\mathrm{pH}$ value

Changes in $\mathrm{pH}$ varied depending on tested nut-dried fruit mixes (Figure 2A, B, C); the least changes in $\mathrm{pH}$ were observed for hazelnuts in separately packaged nuts (6.9 to 6.33) and the greatest $\mathrm{pH}$ drop was detected in nut-dried fruit mix \#2 (6.9 to 6.08).
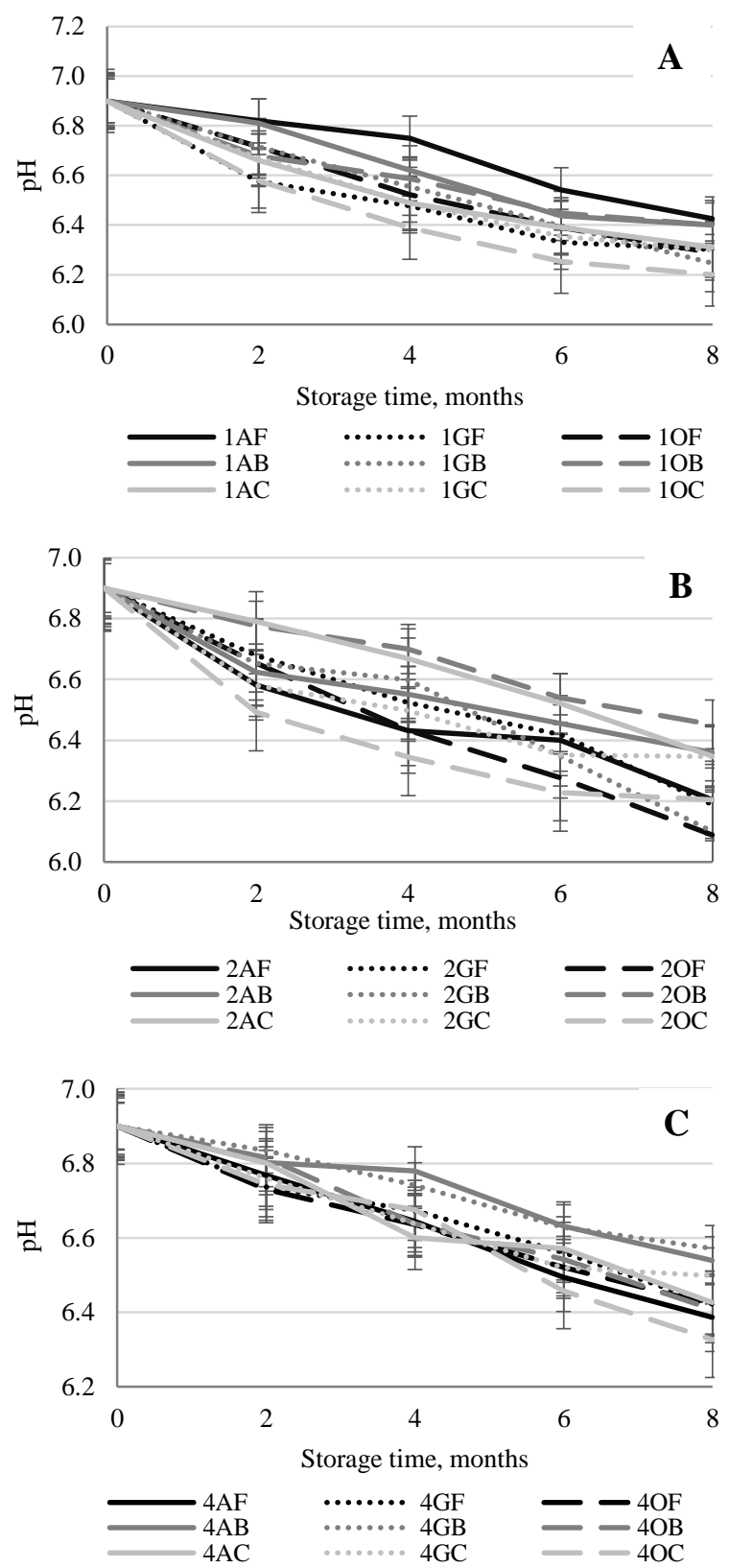

Figure 2. pH dynamics in hazelnuts during storage A - nut-dried fruit mix \#1, B - nut-dried fruit mix \#2, $\mathrm{C}$ - separately packaged nuts

Packaging conditions which were able to have the least effect on hazelnut $\mathrm{pH}$ during storage were as follows: biodegradable PLA with air ambience of oxygen absorbent (6.57) for separately packages nuts, 
biodegradable PLA with air ambience (6.45) for nutdried fruit mix \#1 and \#2.

Changes in water activity

Water activity of hazelnuts in nut-dried fruit mix \#1 (Figure 3A) showed the greatest changes ( 0.421 to 0.553) in metalized packaging (PET / metPET / LDPE) with modified atmosphere environment (sample 2GF).
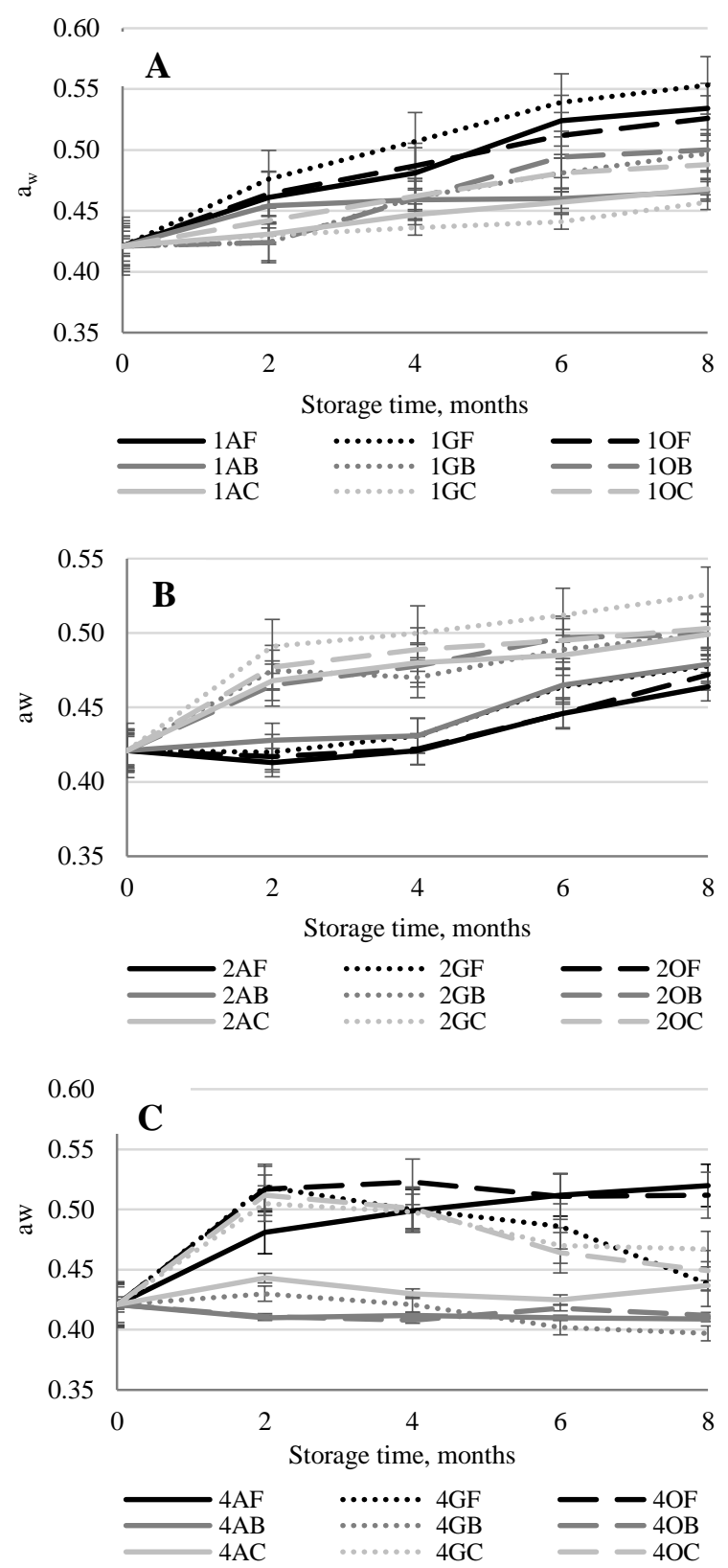

Figure 3. Water activity dynamics in hazelnuts during storage

A - nut-dried fruit mix \#1, B - nut-dried fruit mix \#2, $\mathrm{C}$ - separately packaged nuts

Hazelnuts in nut-dried fruit mix \#2 (Figure 3B) had the highest water activity increase (0.526) in BOPP / EVOH / LDPE packaging with modified atmosphere environment.
Separately packaged hazelnuts (Figure 3C) had the greatest water activity increase in PET / metPET / LDPE packaging with oxygen absorber (0.537).

Chosen packaging materials and packaging environments did not have a significant effect on water activity of hazelnuts during 8-month storage ( $>>0.05)$.

Guiné et al. (2014) previously reported water activity of 0.53-0.58 for hazelnuts, which is in agreement with our results. According to Syamaladevi et al. (2016), water activity of 0.6 and lower indicated lower incidence of microbial growth in foods.

\section{Peroxide value changes in nuts}

Initial hazelnut peroxide value was $0.38 \mathrm{mEq} \mathrm{O} \mathrm{kg}^{-1}$ oil (Figure 4), which increased in all packaging conditions during storage. The greatest changes were observed in nut-dried fruit mix \#1 and the least changes - in separately packaged hazelnuts in biodegradable packaging with oxygen absorber.

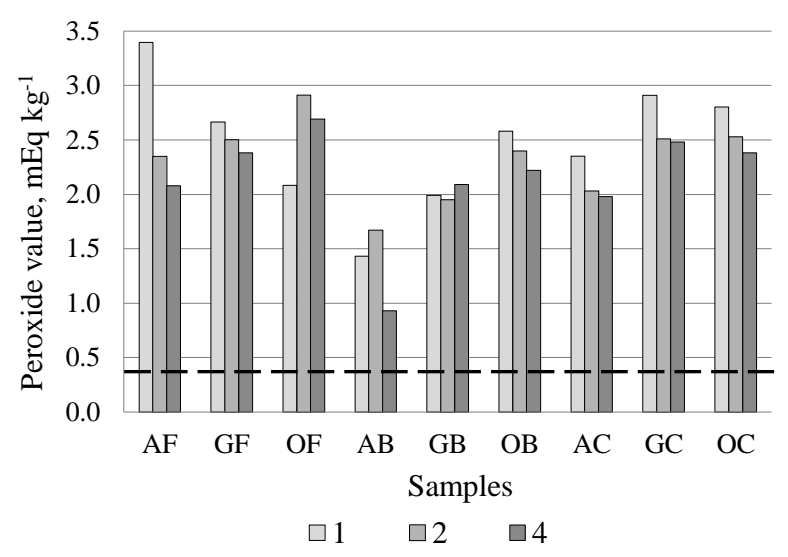

Figure 4. Peroxide value of hazelnuts in different packaging materials and environments after 8-month storage

1 - nut-dried fruit mix \#1, 2 - nut-dried fruit mix \#2, 4 - separately packaged nuts

- - - dashed line represents initial peroxide value

According to Özdemir et al. (2001), peroxide value ranges from 0 to $3.6 \mathrm{mEq} \mathrm{O} \mathrm{kg}^{-1}$ for unprocessed hazelnut oil. Chlebowska-Śmigiel et al. (2008) reported an increase from 0.12 to $0.49 \mathrm{mEq} \mathrm{O}_{2} \mathrm{~kg}^{-1}$ after 3-month storage, whereas Ghirardello et al. (2014) showed peroxide value of $0.17 \mathrm{mEq} \mathrm{O}_{2} \mathrm{~kg}^{-1}$ after 8-month storage and $0.62 \mathrm{mEq} \mathrm{O} \mathrm{kg}^{-1}$ after 12-month storage of hazelnuts. An increase to $2.5 \mathrm{mEq} \mathrm{O} \mathrm{kg}^{-1}$ after 50-day storage was reported by Cam and Kilic (2009), concluding that storage time has a significant effect on peroxide value in hazelnuts.

\section{Hardness changes in nuts}

Changes in hardness were observed for all hazelnut samples (Figure 5); initial hazelnut hardness was $123.51 \pm 5.42 \mathrm{~N}$. The lowest hardness reduction was obtained for separately packages hazelnuts (nuts \#4) in biodegradable packaging with oxygen absorbent and modified atmosphere environment.

Hazelnuts of nut-dried fruit mix \#1 and \#2 in modified atmosphere packaging regardless of packaging materials 
showed a similar reduction in hardness after 8-month storage.

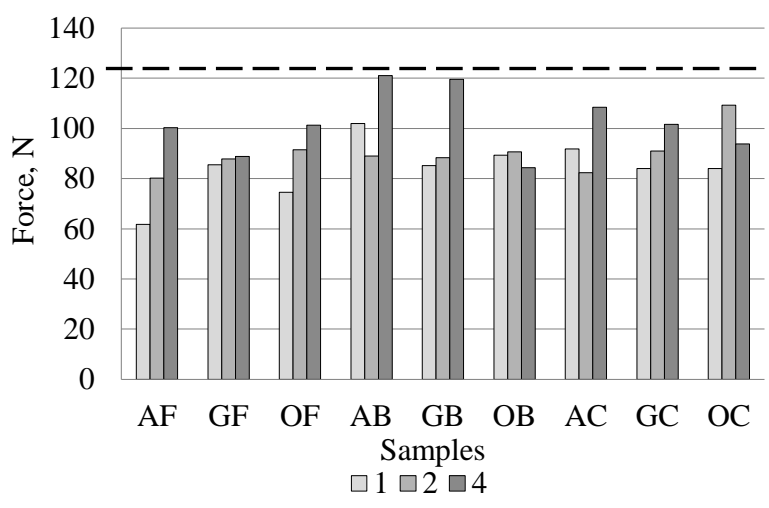

Figure 5. Hardness of hazel nuts after 8-month storage

1 - nut-dried fruit mix \#1, 2 - nut-dried fruit mix \#2, 4 - separately packaged nuts

--- dashed line represents initial hardness

With regards to hazelnuts of nut-dried fruit mix \#2, hardness levels after storage did not differ significantly ( $>0.05)$ among samples, with the exception of sample OC (BOPP / EVOH / LDPE, air ambience), where we observed significantly lower hardness reduction compared to the initial hazelnut hardness value.

Hardness values of 427 to $636 \mathrm{~N}$ have been reported previously for fresh hazelnuts (Valentini et al., 2005).

\section{Colour changes in nuts}

The most noticeable colour changes, expressed as total colour difference, were observed for hazelnuts of nutdried fruit mix \#2 in biodegradable packaging (Figure 6) after 8-month storage. In all samples, except hazelnuts of nut-dried fruit mix \#1 and separately packaged nuts (nuts \#4) in BOPP / EVOH / LDPE packaging with modified atmosphere environment, total colour difference exceeded 10 units.

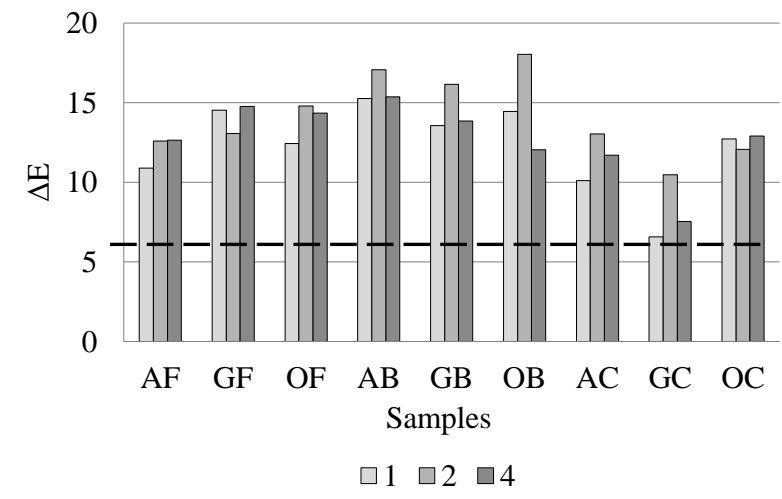

Figure 6. Total colour difference of hazelnuts after 8-month storage

1 - nut-dried fruit mix \#1, 2 - nut-dried fruit mix \#2, 4 - separately packaged nuts

- - - dashed line represents a great total colour difference $\left(\Delta E^{*}>6\right)$ (Andrés et al., 2016)

According to several scientists Cserhalmi et al. (2006) and Andrés et al. (2016), it is possible to analytically classify colour differences in at least five colour difference groups - starting with not noticeable to great differences. Most of the samples exceeded category of great colour differences $\left(6<\Delta E^{*}<12\right)$. Samples in $\mathrm{BOPP} / \mathrm{EVOH} / \mathrm{LDPE}$ packaging with modified atmosphere environment showed the greatest potential in preserving colour of hazelnuts in all nut-dried fruit mix samples.

In addition, Fernández-Vázquez et al. (2013) reported $\Delta E^{*}$ of 2.8 as the colour difference threshold which can be observed by consumers and untrained panellists. This would suggest that none of the tested packaging materials and environments were able to preserve the colour of hazelnuts below the total colour difference limit, which can be easily observed by consumers.

The obtained results raise the question on the quality of nuts in bulk purchased by the distributor and the conditions distributor stores the produce before packaging and retail. It is possible that the initial quality of hazelnuts plays an important role in maintaining their quality during storage, as indicated by the results of hardness, colour and peroxide value.

\section{Conclusions}

The results of moisture content, $\mathrm{pH}$, hardness, colour, water activity and peroxide value testing during 8-month storage showed that the most suitable packaging materials to ensure quality of hazelnuts in nut-dried fruit mixes are biodegradable PLA and BOPP / EVOH / LDPE packaging. With regards to the effect of packaging technologies on product quality, the best results were obtained when modified atmosphere packaging or active packaging was used.

\section{Acknowledgment}

This research was supported by Gemoss Ltd.

\section{References}

1. Andrés V., Villanueva M. J., Tenorio M. D. (2016) The effect of high-pressure processing on colour, bioactive compounds, and antioxidant activity in smoothies during refrigerated storage. Food Chemistry, Vol. 192, p. 328-335.

2. Cam S., Kilic M. (2009) Effect of blanching on storage stability of hazelnut meal. Journal of Food Quality, Vol. 32(3), p. 369-380.

3. Chlebowska-Śmigiel A., Gniewosz M., Gąszewska M. (2008) An attempt to apply a pullulan coating to reduce oxidative changes and mass loss in nuts during storage. Polish Journal of Food and Nutrition Sciences, Vol. 58(1), p. 79-84.

4. Cserhalmi Z., Sass-Kiss A., Tóth-Markus M., Lechner N. S. (2006) Study of pulsed electric field treated citrus juices. Innovative Food Science \& Emerging Technologies, Vol. 7(1-2), p. 49-54.

5. Fernández-Vázquez R., Stinco C. M., Hernanz D., Heredia F. J., Vicario I. M. (2013) Colour training and colour differences thresholds in orange juice. Food Quality and Preference, Vol. 30, p. 320-327.

6. Ghirardello D., Zeppa G., Rolle L., Gerbi V., Contessa C., Valentini N., Botta R., Griseri G. (2014) Effect of different 
storage conditions on hazelnut quality. Acta Horticulture, Vol. 1052, p. 315-318.

7. Guiné R. P. F, Almeida C. F. F., Correia P. M. R. (2014) Evaluation of preservation conditions on nuts properties. In: 9th Baltic Conference on Food Science and Technology "Food for Consumer Well-Being" FOODBALT 2014 Conference proceedings, Jelgava, Latvia, p. 271-275.

8. Herbello-Hermelo P., Lamas J.P., Lores M., DominguezGonzález R., Bermejo-Barrera P., Moreda-Piñeiro A. (2018) Polyphenol bioavailability in nuts and seeds by an in vitro dialyzability approach. Food Chemistry, Vol. 254, p. 20-25.

9. Kapetanakou A.E., Skandamis P.N. (2016) Applications of active packaging for increasing microbial stability in foods: natural volatile antimicrobial compounds. Current Opinion in Food Science, Vol. 12, p. 1-12.

10. Licciardello F. (2017) Packaging, blessing in disguise. Review on its diverse contribution to food sustainability. Trends in Food Science \& Technology, Vol. 65, p. 32-39.

11. McMillin K. W. (2017) Advancements in meat packaging. Meat Science, Vol. 132, p. 153-162.

12. O’Neil C. E., Keast D. R., Nicklas T. A., Fulgoni V. L. (2012) Out-of-hand nut consumption is associated with improved nutrient intake and health risk markers in US children and adults: National health and nutrition examination survey 1999-2004. Nutrition Research, Vol. 32, p. 185-194.
13. Özdemir M., Açkurt F., Yildiz M., Biringen G., Gürcan T., Löker M. 2001. Effect of roasting on some nutrients of hazelnut (Corylus Avellana L.). Food Chemistry, Vol. 73, p. 185-190.

14. Ozturk I., Sagdic O., Yalcin H., Capar T. D., Asyali M. H. (2016) The effects of packaging type on the quality characteristics of fresh raw pistachios (Pistacia vera L.) during the storage. LWT-Food Science and Technology, Vol. 65, p. 457-463.

15. Pérez-Gago M.B., Rhim J.W. (2014) Coating and film materials: Lipid bilayers and lipid emulsions. In: Innovations in Food Packaging. 2nd ed. S. T. Taylor (ed). New York: Academic Press, p. 325-350.

16. Schlörmann W., Birringer M., Böhm V., Löber K., Jahreis G., Lorkowski S., Müller A.K., Schöne F., Glei M. (2015) Influence of roasting conditions on health-related compounds in different nuts. Food Chemistry, Vol. 180, p. $77-85$.

17. Syamaladevi R. M, Tang J., Villa-Rojas R., Sablani S., Carter B., Campbell G. (2016) Influence of water activity on thermal resistance of microorganisms in low-moisture foods: A Review. Comprehensive Reviews in Food Science and Food Safety, Vol. 15(2), p. 353-370.

18. Valentini N., Rolle L., Zeppa G. (2005) Characterisation of hazelnut varieties by texture analysis. Acta horticulturae, Vol. 686(686), p. 485-489. 